\title{
The Use of Gesture Techniques in Children's Singing
}

* Liao, M.Y. Ming Hsin University of Science \& Technology (Taiwan)

melodyliao@must.edu.tw

\author{
Davidson, J.W. The University of Sheffield (UK) \\ j.w.davidson@shef.ac.uk
}

\begin{abstract}
The purpose of this study was to begin to explore the link of gesture and voice when teaching children and to examine how the children used these gestures in singing. Semi-structured interviewing technique and observation were used extensively to collect information from the respondents. Five children were asked to participate this preliminary work individually. The results demonstrated that there was a link between children's singing voice and their use of gesture by observing the Dalcrozian mirror and follow games. The functions of gestures could be defined as being for focus, guidance, support, good intonation, and sensation. In addition, some specific teaching techniques were required for achieving a more effective gesture and a more successful sound. Gesture techniques helped the children to improve their vocal techniques and correct their vocal faults. This study opened the field for the full study of gesture in aiding children's singing.
\end{abstract}

Keywords: gesture, singing, Dalcroze, vocal technique, children 


\section{Background}

As far back as the Classical Greek writings on music, an intimate link between musical sound and bodily movement has been discussed (Barker, 1989). In recent decades, cognitive and music psychologists have become interested in discovering the relationship between performance and bodily movement. In Davidson's work (1991, 1993, 1994, 1995), a series of explicit studies into bodily movement during performance showed a significant link between movement and performance. By observing a pianist in two performances, the results showed the expected relationship between the movement size and expression, for example, the more intense the expressive intention, the larger the movement (Davidson 1994, 2001). In other words, bodily movement reflects the performer's musical expression. Similarly, Clarke and Davidson (1998) undertook two case studies of a pianist and found there were some expressive gestures for particular musical meanings. Body movement plays a vital role in performance, which can help determine the interpretation of the musical expression through the performer's conception of the musical structure.

The use of motions and gestures has become a critical part of performing art in classical opera or stage singing (Ehmann, 1968; Liao, 2004). Body movement and gesture are regarded not only as the physical support of singing process, but also play an important role in expressing emotion (Davidson, 2001; Davidson \& Coimbra, 2001; Liao, 2004). It can be observed that opera singers tend to open their arms gradually when singing a final long note. This supports Davidson's (2001) suggestion that gesture 
not only helps a vocal expression but also helps support, and sustain the singing voice. Therefore, gesture might serve another function in facilitating vocal technique. More precisely, the strong interrelation of voice and gesture can be easily discovered through some actions. For instance, the louder the voice, the more forceful the gesture; and the softer the voice, the gentler the gesture. The degree of vibrato used is also reflected in the gesture. For instance, singers tend to open their arms gradually while singing a crescendo passage and close their arms gradually while singing a decrescendo one.

During the past quarter-century, research on the use of movement as a rehearsal instruction technique has been ardently discussed and its practice has become more widespread (Ehmann, 1968; Gordon, 1975; Weaver, 1977; Henke, 1984 \& 1990; Apfelstadt, 1985; McCoy, 1986; Hylton, 1987; Wis, 1993 \& 1999; Hibbard, 1994; Caldwell, 1995; Aylen, 1998; Chagnon, 2001; Liao, 2002). Some choral directors use it as the primary rehearsal approach, whereas others use it as a supplemental method. For the majority, the idea of adopting movement in the choral context was influenced by Dalcroze Eurhythmics, which is a method to study and experience musical elements through movement. The Dalcroze Eurhythmics is based on the premise that rhythm may be found in the natural rhythms of the human body (Choksy, et al., 1986:27). There are three branches of this method: Rhythmics, solfège and improvisation. Rhythmics explores the time-space-energy relationship of body movements; solfège emphasizes pitch training and harmony; and improvisation is concerned with manipulating the musical elements, especially at the keyboard. Traveling through space with the whole 
body apparently helps students to develop kinesthetic imagination and kinesthetic (muscular) memory, which are regarded as a very important ability in learning music. In particular, singing is a physical activity of whole body which is needed to be trained.

In addition to Dalcroze approach, Kodaly's method is also popular used in choral singing. Kodaly's solfa combining with hand signs provides a visualization in space of the high-low relationship among the notes being sung (Choksy, 1999). Through kinaesthetic sensation, it makes tonal memory both quickly accomplished and more secure. Apfelstadt (1988) believed that hand levels is an effective strategies to reinforce intervallic feeling and enhance pitch perception in the context of vocal development. Steeves(1985) also found that children who use hand signs identify intervals more quickly and correctly than children who do not. Showing the pitch by gesture has been proved to improve student's melodic progression (Phillips, 1992; Mueller, 1993; Langness, 1997). Therefore, the application of hand sign or gesture in developing singing is regarded as an invaluable approach.

The application of gesture technique in choral singing has been examined in the doctoral theses of Wis (1993), Hibbard (1994), Chagnon (2001) and Liao (2002). They all believe gesture and movement helped transfer an overt activity into an imagined activity. That is, something experienced in the body, through a gesture or movement, can be stored in the memory and can be internalized so that it can be drawn upon at a later time to recall the physical sensations without the individual actually having to make the gesture. The researchers discovered that gestures did help the singers to have 
motor sensations, which assisted in the development of sound sensation, improving vocal technique as a result (Apfelstadt, 1984 \& 1985; McKinney, 1994; Greenhead, 2002). Shehan (1987) and Taylor (1989) believed that a gesture and physical movement promote musical memory. In applying gesture technique, singers use their gestures to make the kinesthetic imagery into a kind of picture for the process of developing musical memory, which improves singing ability.

For rehearsal efficiency, Wis (1993), Hibbard (1994), Aylen (1998), Chagnon (2001) and Liao (2002) describe the advantages of using gestures, e.g., improving singers' concentration and group dynamics, saving rehearsal time, creating an active choral environment and a positive rehearsal atmosphere. For singers and directors, the use of gesture has also described to be of benefit, e.g., it is easy to establish a common language between singers and directors as gesture provides visual assessment for conductors and makes the singing easier. Summarizing the principles for the application of movement in choral singing as follows: (1) gesture conveys what words cannot; (2) kinaesthetic experience facilitates learning, (3) gesture promotes musical memory; and (4) gesture as a metaphor aids music learning.

The work mentioned above has summarized, categorized, and analyzed several gestures to correct certain singing faults and facilitate singing (e.g. intonation, tone quality, articulation). Generally speaking, a gesture may serve several purposes. For instance, a simple circular hand gesture can be used to improve intonation, enhance flow, encourage an open throat and lift the soft palate. The main functions of these gestures 
are used to improve vocal technique and to correct vocal faults. They fall into two broad categories based on their functions:

1. Direct: the gesture is a direct description of the sensation of the sound which serves as a metaphor. The majority of these gestures are for improving motor image, tone quality and expression such as circling for legato, and pointing for vocal maintenance and focus.

2. Indirect: the gesture has a less direct effect one a vocal line. The main functions of these gestures are for correcting the faults in voice or motor images. For example, simply lifting the hand in order to raise a flattened song tone (Liao, 2002: 22).

The previous work mentioned above has provided insight into the clarification of some gestures and movement for particular vocal techniques, but fewer specific sources exist examining how children master with voice and gesture and put them together in singing. It appears that no specific study exists which traces how children learn the gestures in developing their voice and singing skills. Therefore, the current study focuses on children's singing, in order to specify how particular gestures can be developed to enhance children's motor images, making singing easier. A qualitative study was carried out to gain more information about how children were perceived to have used gesture in singing. This investigation may be regarded as being of a preliminary nature.

The purposes of this study were:

1. To explore the relationship between voice and gesture/movement. 
2. To examine the gesture techniques for children's singing.

3. To examine the functions of using gesture in singing.

\section{Method}

As a first step towards understanding how children might perceive and respond to gesture and singing, it was decided to work intensively with a small number of students and so obtain qualitative data from them. Semi-structured interviewing technique and observation were used extensively to collect information from the respondents. Five children of either ten or eleven years old, were randomly selected to take part in the study. They were interviewed individually. All of them had a positive attitude towards music but no special training in singing, movement, dance or gymnastics.

One experienced voice and movement teacher served as the interviewer. The interviewer is the researcher. She has ten years of professional experience working with the age group studied. The interviews all took place in the Music Department of Sheffield University. In order to observe interviewees' gestures and movement, video and audio recordings were made of the interviews. The children showed that they were not fearful of performing in front of the video camera. The open style of the interview allowed the children to discuss and express their experiences of using gestures and to create their movements. In addition, they were asked to show some gestures for particular vocal patterns. Each interview took approximately one hour.

The interview was divided into three sections: (a) mirror game, (b) follow game, 
and (c) creating gestures for particular vocal patterns. The following figure shows the method of data collection, contents, and analysis.

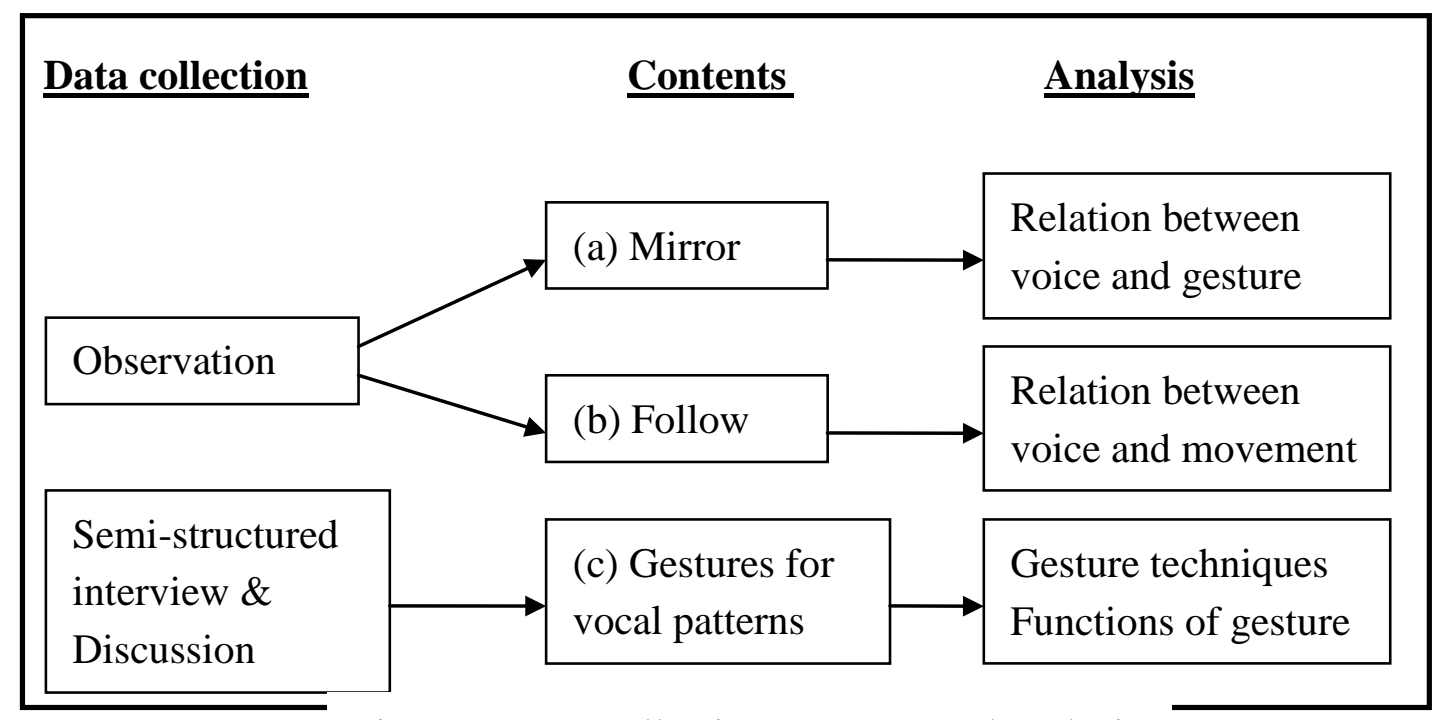

Figure 1. Data collection, contents and analysis

\section{(a) Mirror game}

Four basic types of Daclroze rhythm are quick reaction, follow, replacement and cannon. A mirror exercise (Dalcrozian follow game) was chosen for the physical warm-up and for the observation of the relation between voice and gesture. In order to demonstrate what should do next, the children were asked to copy the interviewer's movement and later the voice of the experimenter who also acted as the leader. Subsequently, the children were asked to create their own gestures and to vocalize a sound for the interviewer to copy. Through the mirroring game, subtle gestures and sounds were explored. 


\section{(b) Follow game}

A Dalcrozian follow game was designed to explore the relationship between the children's movement and voice. In the beginning, the children were asked to follow the interviewer's movements (traveling in space) and then imitate the voice accompanying with movement. Afterwards, they were asked to explore their own movements and voice. In other words, they made sound with movement spontaneously. The main observation was drawn from children's spontaneous movements while making sound.

\section{(c) Creating gestures for particular vocal patterns}

In order to understand how children described sound by gesture and how they master with voice and gesture, seven popular vocal warm-up patterns (see Table 1) were used for singing task in the final section of the interview. The children described the patterns, which were given by the interviewer, by using gestures and then applied them to singing. The suggested gestures were given by the interviewer in order to establish which gesture the children found was best and to explore their accounts for why it was most effective. All the suggested gestures were drawn from Wis's (1993) and Hibbard's (1994) thesis which were proved effective. During this section of asking children to create their own gestures for particular vocal patterns, discussions were involved. 
Table 1: Seven popular vocal patterns and their suggested gestures

\begin{tabular}{|c|c|}
\hline Vocal pattern & Suggested Gesture \\
\hline 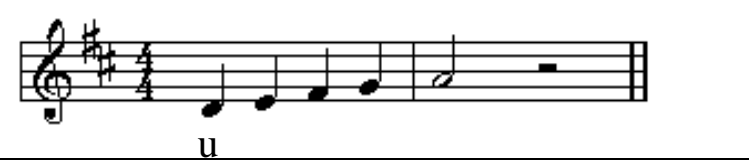 & Pushing \\
\hline 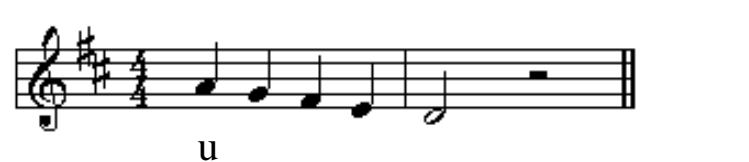 & Raising hand \\
\hline 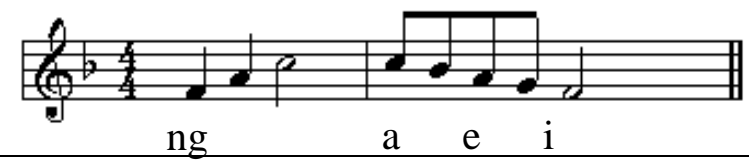 & Side swinging \\
\hline 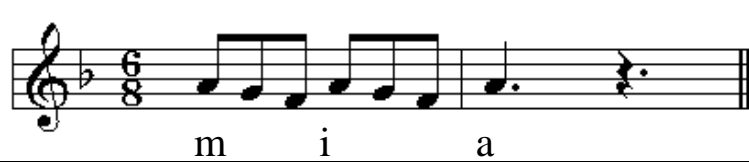 & Ear side circling \\
\hline 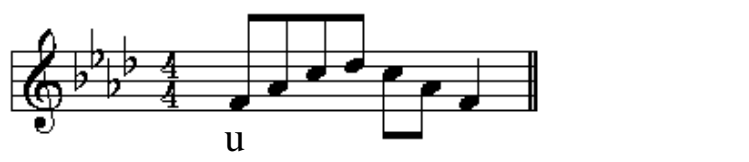 & Gathering \\
\hline 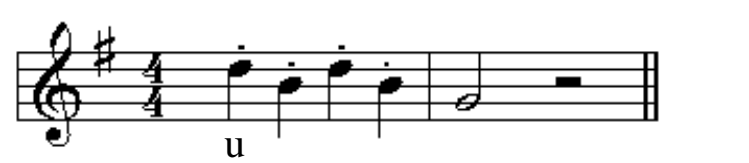 & Flicking \\
\hline 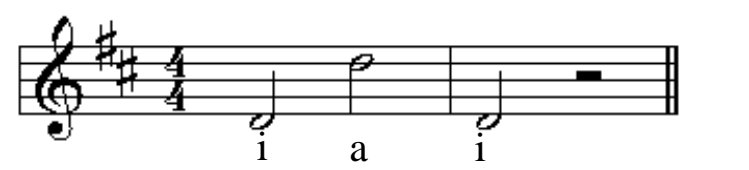 & $\begin{array}{l}\text { Swinging side to side } \\
\text { Pushing down and releasing }\end{array}$ \\
\hline
\end{tabular}

Analysis of the data collected from this study began with a review of the videotapes.

The full video data from the section of mirror, follow, and creating gestures for particular vocal patterns were reviewed and transcribed. The field notes from the discussions in the interview were also made. Gestures and movements were identified, described, and analyzed by the same two experienced valuators. The main focus of analysis was to explore the link of gesture/ movement and voice. The contents of analysis for gesture/movement and voice were shown in table 2. 
Table 2. The contents of analysis for gesture/movement and voice

\begin{tabular}{|l|l|}
\hline Gesture \& Movement & Characteristics of voice \\
\hline Hand level & Pitch level \\
\hline Direction of hand moving & Melodic contour \& Emotional state \\
\hline Size of movements & Dynamic levels \\
\hline Distance of palms \& weight & Tone quality \\
\hline Continuity of movement & Articulation \\
\hline
\end{tabular}

The interview transcription of final section focused on (a) how gesture aided children's singing, (b) how children described the particular vocal pattern with gesture, and (c) if any special techniques were needed for making a better quality of gesture. The interview transcription of discussion was used for examining the functions of using gesture in singing. It was assumed that better gesture quality would cause more successful voice. Therefore, the analysis of gesture quality is the main focus of the final section. The judgment of gesture quality includes body efficiency (balance and control, alignment, centeredness, grounding and coordination), mastery of gesture technique (gesture accuracy, expression, flow and ease in performance, flexibility), and coordination of voice and gesture (blending voice with gesture, time-space). The video taped were repeatedly reviewed, described and analyzed by two experienced valuators. The gesture quality was evaluated first. Secondly, children's singing was described. The link between gesture quality and singing performance were then compared. Some techniques were found to produce more effective gestures for vocal output. 


\section{Results}

After the interviewer analyzed and observed the movements and gestures, and the interview transcripts, the link between voice and gesture was explored.

\section{The Link Between Voice and Gesture/Movement}

The main aim of the mirror and follow games in the interviews was to observe how the children accompany body movement and gesture with voice, and vice versa. The following list shows the relationship between children's gestures and voice which emerged in the exercises and were observed in the analysis:

1. The level of hands reflected the height of pitch. For example: above the head (top) for high notes; for low notes children bent forwards to touch their toes.

2. The direction of hand moving reflected the melodic contour and emotional state. For example: pushing hands down for descending and sad; rising hands for ascending and happy.

3. The size of movement reflected the different dynamic levels. For example: bigger movement for louder voice; smaller movement for softer voice.

4. The distance of the palms of the hands reflected the tone quality. For example: clasped hands for a narrow sound; open arms and palms for a broad sound.

5. The continuity of movement reflected the articulation. For example: continuous and smooth movement for legato; discontinuous movement for staccato.

6. The weight of movement reflected the quality of sound. For example: heavy movement for dark and broad sound; light movement for light and ringing sound. 
Sometimes the children performed heavy or light movement by pretending to be animals. For instance, they moved like an elephant, which resulted in a heavy and loud sound.

\section{Gesture Technique}

Although gestures helped the children to sing better most of the time, not every gesture was successful in improving the voice or correcting vocal faults. Thus it seems that an effective gesture demands some prerequisites. From detailed observation and analysis, the following techniques were found to produce more effective gestures for vocal output:

\section{Verbal imagery, direction and feedback}

Sometimes, verbal imagery accompanying the gesture made it more effective, resulting in a better sound. For example, 'imagine you are pulling a piece of elastic from a relaxed to a tight position'. You have to imagine that the sound is inside the elastic which you must make as straight and as tense as possible. It helped the children to feel a sensation thus making the sound more vibrant. In addition to verbal imagery, giving some vocal directions (e.g. "Look at your hands, pulling away as slow as possible, keep the last note as long as possible as well.”) and feedback (e.g. "Good! The voice goes straight and forward") also produced better results because most of the children did not have an idea about what kind of sound they needed to produce. Through verbal imagery and directions, the 
children seemed to gain a clearer picture of the quality of sound they needed to make.

\section{Concentration and eye focus were requirements for certain gestures}

Some gestures improved the focus of tone, such as 'pointing' and 'pulling' which needed more concentration to undertake than 'swinging'. Therefore, looking at the hand gestures in order to focus on tone and even scales can help, especially for sustaining the last long note, which needs more concentration. From the observations, most of the children could not sustain long notes because they were lacking a good focus or mental concentration.

\section{The time-space of gesture with voice}

The gesture seemed not to be effective unless the time-space of the gesture and voice matched. Time-space here is defined as an effective match of the gesture length and pace and the exact note. For example, when singing the 1-8-1 sliding, 1 (fingers interlaced and palms facing down, placed in front of the chest-- relax)-8 (pushing hands down)-1 (back slowly). Figure 2 shows the effective and

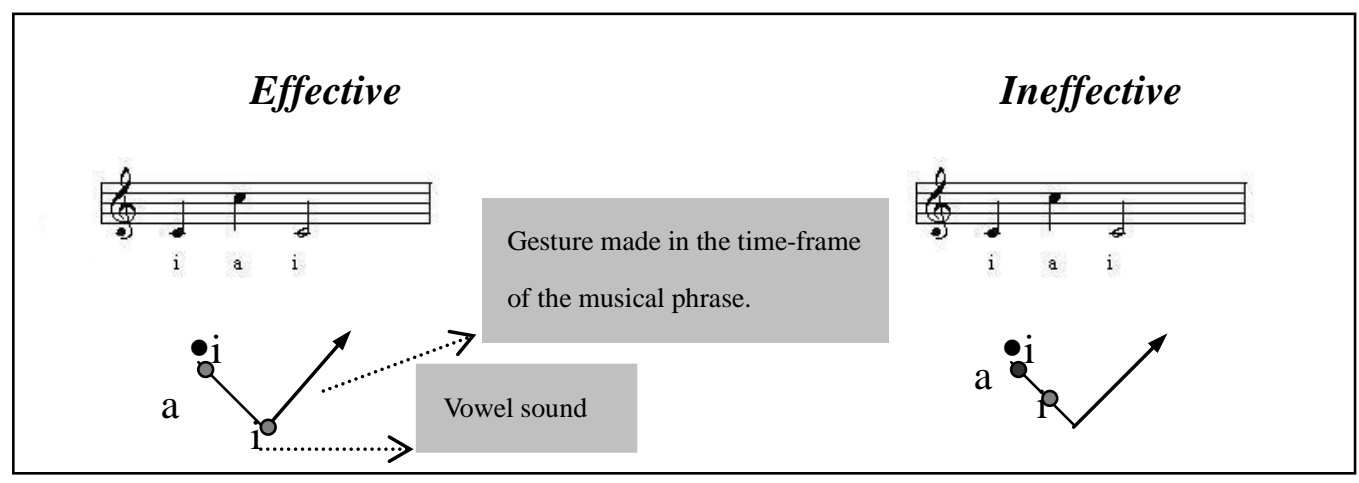

Figure 2 The Effective and Ineffective Time-space of

Voice and Gesture for Octave Sliding 
ineffective time-space, if the children made a movement that was pushing faster than their voice, it created a throaty vocal sound on the top note and constricted the sound of the last note. Generally, the children were unable to manage the sensation of stretching and sliding for the big jump. From observing the children, all of them had a habit of doing the gesture faster than their sound. It could be argued that their gesture therefore reflected their air status.

\section{The direction of hand gestures}

It appeared that tone quality depended on the shape of the hand gestures. An effective gesture depended on a correct direction of hand gesture. For example, 2.5 times circling for the vocal pattern of

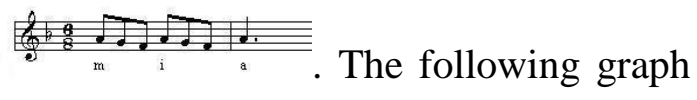
(Figure 3) shows what is an effective and an ineffective gesture direction.
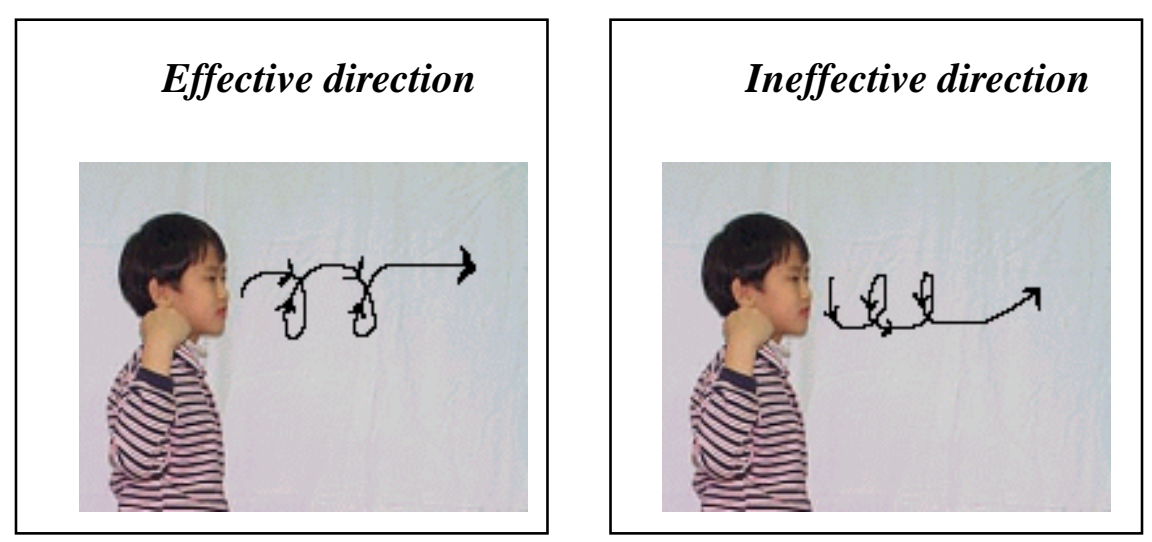

Figure 3 An Example of an Effective and an Ineffective Gesture Direction

It is a well-established singing technique (Mckinney, 1994; Phillips, 1992) that lifting the soft-palate is important at the onset of singing in order to produce an 
ideal sound. According to the acoustic analysis, it looks like that a clockwise movement seemed to create a comfortable, smooth and round sound (effective direction). Conversely, a counterclockwise movement seemed to create a 'throaty' and constricted sound especially on the first notes (ineffective direction).

\section{The placement of hand level at the onset}

Hand height was very important for a good beginning. Placing hands too low for high notes appeared here to give a 'throaty' and heavy sound. Therefore, it seems vital for the conductor/director to show the performers where to start.

\section{The demonstration of gestures}

From the observation, the children were sometimes unable to copy the gestures correctly, such as 'circling' and 'flicking', because the conductor/director did not show the gestures in an appropriate way (i.e., the reverse of the gesture she wanted the children to perform). As a result, the children drew the circle backwards instead of forwards. Therefore, it seems that when teachers demonstrate the gestures, it appears that they need to be careful. Some gestures such as 'pulling', 'pushing' or 'swinging' it might be necessary for the conductor/director to face the singers; in 'pointing', 'circling' or 'flicking' it might be better for the conductor/director to present to the singers at a 45 degrees angle. Alternatively, the conductor/director might be best to demonstrate the gesture by facing the singers with a verbal instruction reminding them, e.g. 'draw a line forward' or 'pull something toward you'. 


\section{More practice to produce better effect}

Gestures were not always effective at the beginning of examples and exercises. It was observed that children made a better sound through practising the gesture. In this sense, it seems necessary for directors to correct singers' gestures in rehearsals.

\section{Expressive gesture causes expressive sound}

Only when the children were able to concentrate and experience the sensation of the gestures could their gestures become expressive. It was observed that the children performed better in voice and gesture and had a more expressive gesture when moving than standing on a spot. It might be that movement activities make them feel at ease and thus more able to imagine something (for instance, "imagine you are walking in a beautiful forest like a mouse") and, therefore, result in a more expressive voice and gesture.

\section{Functions of Gesture in the Assistance of Children's Singing}

The following section explores how gesture seemed to help the children in their singing. The five children all stated that gesture helped them sing more confidently. In addition, they also found a difference between singing with and without gesture. Most of the time, they preferred using gesture and felt that gesture helped them, but at one point, one of the children said:

I think without gesture is better because I don't need to do two things at the same time. (C3) 
According to this point, there could be a potential difficulty of coordination on two tasks. But, all the children stated that gestures helped them to sing better during the interview. Generally speaking then, the results of the study suggest that the functions of gestures could be defined as being:

\section{For focus}

Gestures helped the children to focus on their tone when they looked at their hands: Having something to look at helped me to focus on the sound. If I had something to look at, then I could focus better. I felt like I don't have a focus without gestures. (C3)

It was observed that the most of gestures (e.g. circling, pulling, pointing) have the function of aiding children to focus on the tone.

\section{For guidance}

Gestures, as a guide, helped to direct the voice and helped with the shape or quality that was required:

The gesture is like a guide. It makes you sing straight or in a circle. I know how to sing with gesture because I taught myself how to sing. (C5)

It tells me what the sound should be like and what sound I need to make. (C1)

Without gesture, you have nothing. If you've got a gesture you can follow it. (C3)

One of the children described the gesture as his teacher. He said: "with this gesture (bouncing), it helps me to sing. In other words, my body teaches me how to sing". 


\section{For support}

Gestures helped to give support to the children's tone especially for the final sustained note:

My hands give me support and tell me where to go. (C2)

If I do this (using a gesture as though pulling a piece of string in different directions-- up and down), it helps give me support so I can keep the last note longer. (C5)

With a "give you" gesture, I felt more supported. (C3)

\section{For tuning}

It was observed that gesture helped the children's pitch accuracy. A simple gesture such as circling or pointing had a very positive effect for sound projection and reaching the correct pitch. One of the children, unable to carry a tune most of the time (and at the age when his voice was changing), said that gesture helped him to reach the right notes and made his voice stable. He said:

...I don't know what's happened. When I use gestures, I can reach the tone. My throat is comfortable as well. (C2)

\section{For sensation}

Gestures gave the children physical sensations so they could make a better, more expressive sound:

Movement and gesture give the sensation of sound. When I lift my heels up and 
down, I will have the feeling of rhythm. (C3)

It helps me to blend the voice and gives me a sensation. When they mix together, then I let them go. So when you sing, then it is easier to come out. It also helps with your expression. (C4)

With gesture, I have some feeling of the sound. Without gesture, then there is no sensation. (C5)

\section{Discussion}

The results of this exploratory study re-invoke previously held views that there is an intimate relationship between voice and gesture/movement and that children can use gesture to facilitate their singing. Thus, in order to achieve a more successful voice, gesture techniques could be used beneficially during practice for children. Indeed, through observation, the children's body movement and gesture reflected the voice quality - the size of movement reflects the different dynamic levels and the continuity of movement reflects the articulation. This is supported by Barker (1989) and Davidson (1991, 1993, 1994a, 1995) who have proposed an intimate link between the type of musical sound achieved and the type of bodily movement used.

Although gesture technique has a positive effect in aiding singing and most children love to use it, not all of the children felt comfortable to use gesture while singing. This might be a challenge for teachers to overcome. Findings from the interviews suggested that metaphor played an important role for the children in 
perceiving the sound especially for the melody contour and dynamics. For example, the children moved their hands from top to bottom when describing the descending passages. Obviously, metaphor has been discussed to be an important point in perceiving and creating music (Lakoff \& Johnson, 1980; Wis, 1993). Showing the pitch by gesture has been proved to improve student's melodic progression (Phillips, 1992; Mueller, 1993; Langness, 1997). Although metaphor helps children to understand abstract concepts (such as tone quality) and perceive pitch or melody more successfully, Greenhead (2002) argued that not all the gestures function as metaphor; furthermore, it may not always work well in developing sensations needed for vocal techniques. For example, the children in this study tended to describe a long note by opening arms - that is a metaphor. But the opening arms applied in singing often caused a serious spreading of the tone and throaty sound. In this case, metaphorical technique does not always work at improving the vocal technique, but it did help children to understand the concepts of music such as dynamic, and melodic contour better. Langness (1997) also pointed out that when students use hand signals to indicate a high note by gesturing above their necks and heads, it often results in an inefficient rising of the larynx and squeezing of the vocal folds. Thus, the current results suggested that it might be important to develop pitch perception in the first stage of learning by adapting a highly metaphorical technique, but this may not be sufficient at a later stage for developing art singing. So, developing an appropriate gesture to usefully build on individuals' natural tendencies seems to be a very important first step. 
Previous studies focus on developing the functions of gesture in improving vocal sound. Nevertheless, the gesture techniques are less discussed and explored. It was observed that some specific gesture techniques were required in order to make a more successful voice during the interviews. Given verbal imagery or verbal directions in an appropriate situation, the children could sing better. Wis (1993) has shown a positive result when using verbal imagery with gesture. According to Funk's (1982) findings, verbal imagery is an especially effective force when vocal skills are lacking. Furthermore, it might be necessary to provide some verbal guide (such as 'focus on your index finger') or feedback ('yes, keep the vocal focus') to accompany the verbal imagination because the beginner singer has a weak sense about what constitutes a good voice. This point is regarded as an important factor to achieve successful singing, which was also proposed by Welch (1985).

From the current investigation, it appears firstly that the main requirement of a gesture is its quality. And secondly, the voice must blend with the gesture (coordination of gesture and voice). According to the interview findings, the time-space of gesture with vocals, the position of each note in the pitch progression, the direction of hand gestures, and the placement of hand level at the onset were the most important points for creating an effective voice by gesture. This was supported by Hibbard's (1994) study who has emphasized the importance of the direction of gesture. Therefore, the gesture is not always naturally effective but needs some techniques. This indicated that the conductor/director needs to explore her own gesture use and understanding as fully as 
possible prior to developing a further study.

According to feedback from the children, the gestures helped them in many ways. They helped to focus the tone, to guide the singing, to support the vocal line, to carry a better tone and to give a sensation of the sound. Therefore, it looks like that gesture might be a good way to facilitate children's singing.

There was a special case in this interview; one of the children could not carry a tune. Through gesture, he gradually produced the correct tune and even a better sound. Because he was at the age of changing voice, it meant that his voice was not stable all the time. However, he managed to produce a stable sound by supporting it with gestures. In other words, the gesture seemed to give him a focus.

\section{Conclusion}

This study has shown a strong link between voice and movement/gesture and makes a strong case to support the existing literature on the role of movement and gesture and its potential for training children to sing. It is very important that teachers know the purpose of each gesture for a particular sound when they are using this kind of gesture technique, so that the gesture can be effective.

Based on the results of this study, several conclusions about using gesture as a training tool for children's singing are drawn:

1. A teacher's verbal direction and demonstration of the gesture should be clear and accurate. In particular, some gestures may need a different position (facing 
the children or standing at a different angle). For example, a good way to demonstrate circling is a $45^{\circ}$ turn, even with the teacher's back to the children, otherwise it is easy for the children to produce a counter-clockwise circling and cause an entirely different effect.

2. Proper feedback is necessary. In particular, verbal imagery is helpful to confirm their gesture correction especially for the children who have less singing experience.

3. Proper modification of the singer's gesture is necessary to obtain optimal vocal effects. One of the advantages of using gesture is that it provides visual assessment for the teachers to quickly pick up which students have not understood the sensation or how much they have done in order to produce the correct sound.

4. Some basic techniques are necessary for an effective gesture. For example, a correct gestural direction, size, position and time-space.

These points suggest that the conductor/director of the current investigation can now move forward to begin to develop further and refine the Dalcrozian principles to develop a thorough and child-friendly gestural vocabulary to aid young children's singing techniques. Although of a preliminary nature, this investigation has provided a critical first systematic study of how gesture and voice interact and this has many existing implications for further research. 


\section{References}

Apfelstadt, H. (1984). Effect of melodic perception instruction on pitch discrimination and vocal accuracy of kindergarten children. Journal of Research in Music Education, 32(1), 15-24.

Apfelstadt, H. (1985). Choral music in motion: the use of movement in the choral rehearsal. The Choral Journal, 25(9), 37-39.

Apfelstadt, H. (1988). What makes children sing well. Update, 27-31.

Aylen, S. (1998). An investigation into the use of movement as a teaching strategy in the choral rehearsal. Unpublished Master Dissertation, Roehampton Institute London.

Barker, A. (1989). Greek Musical Writings, Volume II, Harmonic and Acoustic Theory. Cambridge: Cambridge University Press.

Caldwell, J. T. (1995). Expressive singing: Dalcroze Eurhythmics for voice. Englewood Cliffs, New Jersey: Prentice Hall.

Chagnon, R. (2001). A comparison of five choral directors' use of movement to facilitate learning in rehearsals. Unpublished Doctoral Dissertation, Arizona State University.

Clarke, E. F. and Davidson, J. W. (1998). The body in performance. In Thomas, W., (ed.): Composition Performance Reception. Aldershot, Hants: Ashgate Publishing Ltd, pp. 74-92.

Choksy, L. et al. (1986). Teaching music in the twentieth century. Englewood Cliffs, NJ: Prentice Hall.

Choksy, L. (1999). The Kodaly method I: Comprehensive music education. NJ: Prentice Hall.

Davidson, J. W. and Coimbra, D. D. C. (2001). Investigating performance evaluation by assessors of singers in a music college setting. Musicae Scientiae, 5 (1), 33-54.

Davidson, J. W. (1991). The perception of expressive movement in music performance. Unpublished Doctoral thesis, City University, London.

Davidson, J. W. (1993). Visual perception of performance manner in the movements of solo musicians. Psychology of Music, 21(2), 103-113. 
Davidson, J. W. (1994). Which areas of a pianist's body convey information about expressive intention to an audience? Journal of Human Movement Studies, 26, 279-301.

Davidson, J. W. (1995). What does the visual information contained in music performances offer the observer? Some preliminary thoughts. In Steinberg (ed.), The Music Machines: Psychophysiology and Psychopathology of the Sense of Music. Hiedelberg, Germany: Springer, pp.103-115.

Davidson, J. W. (2001). The role of the body in the production and perception of solo vocal performance: a case study of Annie Lennox. Musicae Scientiae, 5(2), 235-256.

Ehmann, W. (1968). Choral directing (Weibe, G. D. Trans.). Minneapolies, MN: Augsburg. (Original work published 1949)

Funk, G. D. (1982). Verbal imagery: illuminator of the expressive content in choral music. Unpublished DMA Dissertation, Arizona State University.

Gordon, L.W. (1975). Body movement exercises in the choral training programme. The Choral Journal, 15(7), 12-13.

Greenhead, K. (2002). Personal Communication with Author.

Henke, H. H. (1984). The application of Emile Jaques-Dalcroze's Solfège-Rhythmique to the choral rehearsal. The Choral Journal, 25(4), 11-14.

Henke, H. H. (1990a). Choral musicianship via the Dalcroze approach. The Choral Journal, 30(3), 225-229.

Hibbard, T. T. (1994). The use of movement as an instructional technique in choral rehearsal. Unpublished Doctoral Dissertation, Oregon University.

Hylton, J. (1987). Keeping your choir on the move. Music Educators Journal, 74(3), 31-34.

Lakoff, G. and Johnson, M. (1980). Metaphors we live by. Chicago: The University of Chicago Press.

Langness, A. P. (1997). Helping children's voices develop in general music education. In Thurman, L. and Welch, G. (eds.), Body mind \& voice: foundations of voice 
education. Minneapolis: The Voice Care Network, pp. 571-581.

Liao, M. Y. (2002). The effects of gesture and movement training on the intonation and tone quality of children's choral singing. Unpublished doctoral dissertation, University of Sheffield.

Liao, M. Y. (2004). A study on the opera singers' (soprano) bodily expression and gesture application. Ming Hsin Journal, 31, 207-222.

McCoy, C. W. (1986). The effects of movement as a rehearsal technique on performance, meter discrimination ability, and attitude of members of high school choral ensembles. Unpublished Doctoral Dissertation, University of Iowa.

McKinney, J. M. (1994). The diagnosis corrections of vocal faults. Genevox Music Group: Nashville, Tennesse, Boardman Press.

Mueller, A. K. (1993). The effect of movement-based instruction on the melodic perception of primary-age general music students. Unpublished Doctoral Dissertation, Arizona State University.

Phillips, K. H. (1992). Teaching kids to sing. New York: Schocken Books.

Shehan, P. K. (1987). Movement: the heart of music. Music Educators Journal, 74(3), 25-30.

Steeves, C. (1985). The effect of Curwen-Kodaly hand signs on pitch and interval discrimination within a Kodaly curricular framework. Unpublished Master Dissertation. University of Calgary.

Taylor, D. (1989). Physical movement and memory for music. British Journal of Music Education, 6(3), 251-260.

Weaver, W. E. (1977). The development of vocal, choral, and musical concepts based on a sequenced integration of vocal-choral principles with interpretive body movement. Unpublished Doctoral Dissertation, Carnegie-Mellon University.

Welch, G. F. (1985). A schema theory of how children learn to sing in tune. Psychology of Music, 13 (1), 3-18.

Wis, R. M. (1993). Gesture and body movement as physical metaphor to facilitate learning and to enhance musical experience in the choral rehearsal. Unpublished Doctoral Dissertation, Northwestern University. 
Wis, R. M. (1999). Physical metaphor in the choral rehearsal: a gesture-based approach to developing vocal skill and musical understanding. The Choral Journal, 40(3), 25-33. 